\title{
Postcranial bones of infant Nacholapithecus: ontogeny and positional behavioral adaptation
}

\author{
Masato NAKATSUKASA ${ }^{1 *}$, Yutaka KUNIMATSU ${ }^{2}$, Yoshihiko NAKANO ${ }^{3}, \mathrm{Naoko} \mathrm{EGI}^{4}$, Hidemi IsHIDA ${ }^{5}$ \\ ${ }^{1}$ Laboratory of Physical Anthropology, Department of Zoology, Kyoto University, Sakyo, Kyoto, 606-8502 Japan \\ ${ }^{2}$ Primate Research Institute, Kyoto University, Inuyama, Aichi, 484-8506 Japan \\ ${ }^{3}$ Department of Biological Anthropology, Osaka University, Suita, Osaka, 565-0871 Japan \\ ${ }^{4}$ Japan Monkey Centre, Inuyama, Aichi, 484-8506 Japan \\ ${ }^{5}$ Department of Human Nursing, University of Shiga Prefecture, Hikone, Shiga, 522-8533 Japan
}

Received 9 April 2007; accepted 5 June 2007

\begin{abstract}
We describe the postcranial bones of a partial skeleton of a male infant Nacholapithecus kerioi (KNM-BG 37800) from the Middle Miocene of Kenya. The skeletal elements are associated with dental remains and its age is presumed to be 6-15 months based on a comparison with an infant Proconsul heseloni with a similar dental growth stage. The postcranial elements include the left scapula, a lumbar vertebra, left distal humerus, right proximal ulna, right radius, right and left proximal femora, a proximal fragment of metatarsal, and proximal and intermediate phalanges. Its body mass was estimated as $3.0 \mathrm{~kg}$ from shaft dimensions of the humerus and femur. At this early postnatal developmental stage, $N$. kerioi can be distinguished from $P$. heseloni in several postcranial features: a caudally projecting lumbar spinous process, strong dorsal divergence of the scapular spine, a coronoid fossa which is more developed than the radial fossa, higher neck shaft angle of the femur, taller trochlea of phalanges, and a lower brachial index. These features, except for the last, agree with the previously proposed positional behavioral reconstruction of $N$. kerioi, in which vertical climbing, orthograde clambering, transferring, or bridging are relatively important compared with $P$. heseloni. The apparently low brachial index results from a comparatively short radius for the predicted body mass. This might imply a relatively slow pace of growth in the radius of $N$. kerioi. However, it might result from body mass overestimation, incorrect length reconstruction, or individual variation. Its interpretation must await further specimens.
\end{abstract}

Key words: postcranial growth, Miocene hominoid, scapula, lumbar vertebra, limb proportions

\section{Introduction}

Postcranial specimens of immature individuals associated with cranial remains that provide information about dental developmental stage are rare in the non-human hominoid fossil record. Until recently, such information was available from only several Proconsul heseloni individuals from Rusinga Island, Kenya (18 Ma) (Napier and Davis, 1959; Walker and Pickford, 1983; Walker and Teaford, 1988; Ward, 1991; Begun et al., 1994; Benyon et al., 1998). In 1998, a partial infant skeleton of Nacholapithecus kerioi (KNM-BG 37800) was excavated from the Aka Aiteputh Formation (ca. $15 \mathrm{Ma}$ ) in Nachola, northern Kenya (Nakatsukasa et al., 2005). Although the preserved postcranial elements are limited, this is the first immature hominoid skeleton from the Middle Miocene of Africa.

Recently, many researchers have focused on reconstructing the life history of fossil non-human primates from dental remains (Lee and Foley, 1993; Kelley, 1997; Kelley et al.,

\footnotetext{
* Corresponding author. e-mail: nakatsuk@anthro.zool.kyoto-u.ac.jp phone: +81-75-753-4107; fax: +81-75-753-4083

Published online 11 August 2007

in J-STAGE (www.jstage.jst.go.jp) DOI: 10.1537/ase.070409
}

2001; Kelley and Smith, 2003; Godfrey et al., 2002, 2006; Schwartz et al., 2002). However, there are as yet few postcranial growth studies of fossil non-human primates. Begun et al. (1994) described numerous $P$. heseloni phalangeal specimens from the Kaswanga primate site (KPS) and noted morphological differences among specimens at different growth stages. However, their focus was principally on the functional adaptation of Proconsul phalanges and the ontogeny itself was not an important issue in their study. The information available from only a few immature skeletons is limited compared to the information that can be expected from an entire ontogenetic series. However, information on morphological change through ontogeny provides a more comprehensive understanding of the structure-function complex compared to data derived solely from adult morphology (Hurov, 1991; Ravosa and Vinyard, 2002).

The purpose of the present study is to describe the morphology of the postcranial skeleton of the KNM-BG 37800 specimen and to compare it with those of conspecific adults and immature $P$. heseloni. Because $N$. kerioi and $P$. heseloni differ in a number of postcranial features (Rose et al., 1996; Nakatsukasa et al., 1998, 2007; Ishida et al., 2004; Nakatsukasa, 2004; Senut et al., 2004), it is of interest to explore whether such differences are observed in the early 
postnatal growth stage. In addition, the KNM-BG 37800 skeleton preserves postcranial parts unknown from previously reported materials. The results of this study are used to reconstruct the postcranial developmental pattern and positional behavior of $N$. kerioi.

\section{Materials}

The KNM-BG 37800 skeleton of $N$. kerioi was excavated in situ at the BG-K site in 1998 (Figure 1). After a few phalangeal fragments were found on the surface, blocks of matrix containing other bones were removed and prepared in the laboratory. The skeleton consists of the following postcranial elements: the left scapula, one lumbar vertebra, left distal humerus, right proximal ulna, right radius, right and left proximal femora, a proximal metapodial fragment and proximal and intermediate phalanges, and dental remains (right and left upper di1, right and left upper dc-dp4, right lower di1-dp4, left lower dc-dp4) (Table 1). None of the detached epiphyses were recovered.

The eight deciduous molars in four jaw fragments are completely erupted, but little occlusal attrition is observed. Deciduous incisors and canines are also unworn. The right M1 is situated in the maxillary fragment and is exposed due to breakage of the alveolar bone. Based on deciduous dental dimensions, this individual is considered a male (Figure 2).

Only adult specimens have been previously described for $N$. kerioi, but infants and juveniles of $P$. heseloni have been described. The comparative fossil samples of the present study are the previously described adult $N$. kerioi specimens (Rose et al., 1996; Ishida et al., 2004) and an infant (KNMKPS individual 4) and juvenile (KNM-RU 2036) of $P$. heseloni. KNM-KPS 4 exhibits a similar (but somewhat later) dental developmental stage to that of KNM-BG 37800 and preserves various elements of the limb skeleton. Its general skeletal size is slightly larger than that of KNM-BG 37800. The central incisor is slightly more worn and the formation of the olecranon fossa articular surface is more advanced compared to the KNM-BG 37800 condition. Beynon et al. (1998) estimated by histological analysis that the eruption of $\mathrm{dm} 2$ had completed around 10 months of age in KNM-KPS 4. Unfortunately, there are no data to estimate the actual age of KNM-BG 37800. However, it is not unreasonable to as- sume that it is broadly in the range of 6-15 months considering individual variation (e.g. Smith et al., 1994) and possible species-specific difference. KNM-RU 2036 is at a much later developmental stage, but the skeleton preserves many body part elements and is the only $P$. heseloni individual for which the brachial index was estimated (Walker and Pickford, 1983).

The body mass of adult $N$. kerioi is estimated as being close to that of adult Papio cynocephalus (Rose et al., 1996; Ishida et al., 2004). Therefore, six infant skeletons of $P$. cyn-

Table 1. List of KNM-BG 37800 skeletal elements

\begin{tabular}{ll}
\hline Suffix & Part \\
\hline A & rt maxilla with dp3-4, unerupted permanent molar \\
B & lt maxilla with dp3-4 \\
C & lt maxilla fragment with unerupted M1 \\
D & rt mandible with dp3-4 \\
E & lt mandible with dp3-4 \\
F & lt mandibular symphysis with di2 \\
G & rt upper dil \\
H & lt upper di1 \\
I & rt lower di1 \\
J & rt lower di2 \\
K & rt upper dc \\
L & lt upper dc \\
M & lt lower dc \\
N & rt lower dc \\
O & lumbar vertebra \\
P & lt scapula \\
Q & rt humerus \\
R & rt radius \\
S & rt proximal ulna \\
T & rt femur \\
U & lt proximal femur \\
V & metapodial proximal end (2nd or 3rd metatarsal?) \\
W & complete middle phalanx \\
X & proximal end of middle phalanx \\
Y & distal end of proximal phalanx \\
Z & distal end of proximal phalanx \\
AA & distal end of middle phalanx \\
AB & distal end of middle phalanx \\
AC & distal end of middle phalanx \\
AD & distal end of proximal phalanx \\
AE & distal end of middle phalanx \\
\hline
\end{tabular}
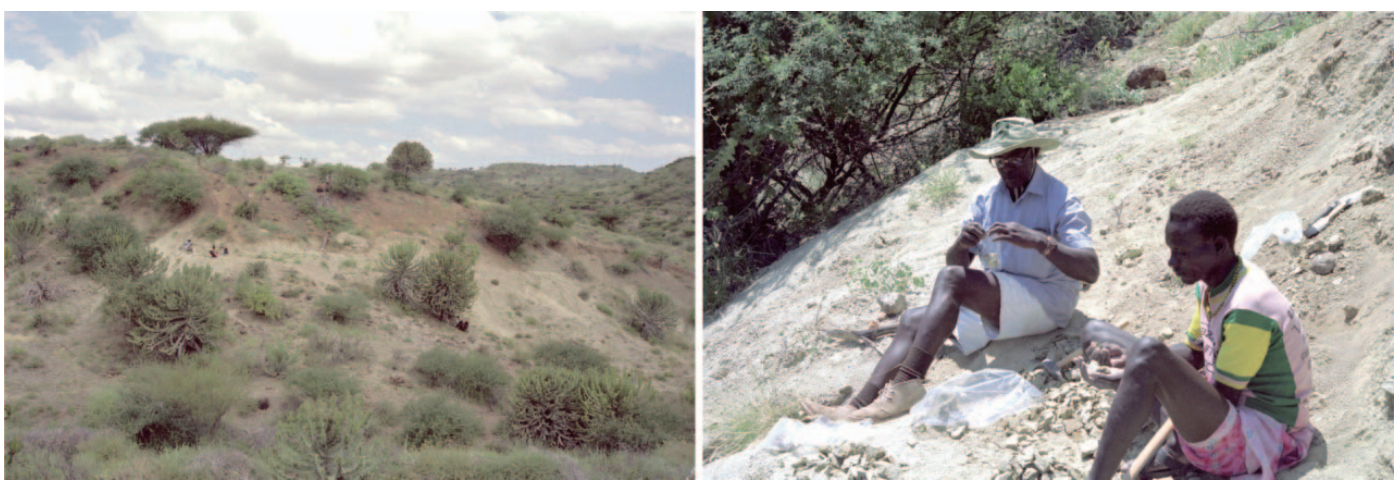

Figure 1. Excavation of KNM-BG 37800. Left: Site BG-K. Right: Mr. Ethekon Kichoto (right) and Mr. Joseph Mutava collecting blocks from the bone bed. 

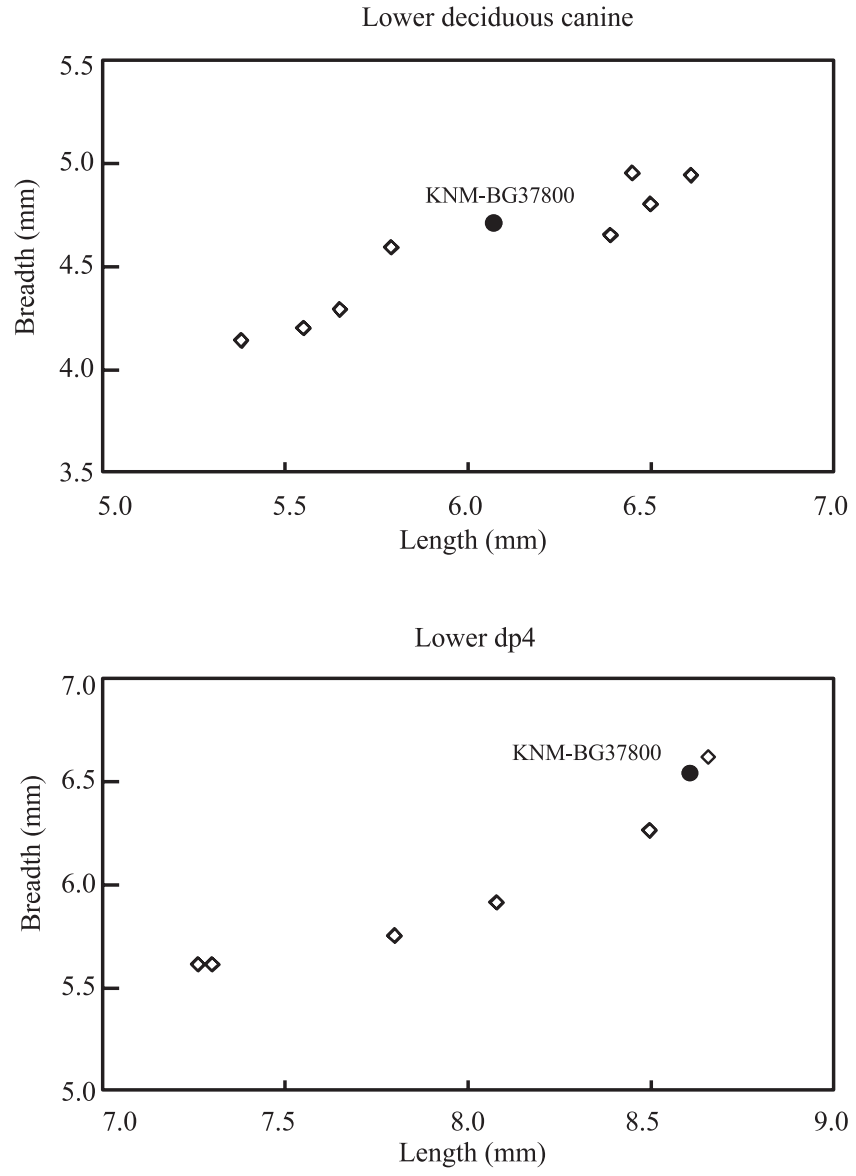

Figure 2. Size comparison of deciduous teeth in N. kerioi. Upper: lower deciduous canine. Lower: lower deciduous fourth premolar. Note dp4 of KNM-BG 37800 (circle) is one of the largest teeth in the comparative sample although its dc size is intermediate.

ocephalus with a similar dental developmental stage to KNM-BG 37800 were used as comparative specimens to evaluate the general developmental pattern. Of the three male and three female $P$. cynocephalus specimens, four have a body mass record with an average of $2.75 \mathrm{~kg}$ (range: $2.5-$ $3.0 \mathrm{~kg}$ ). To estimate the body mass of KNM-BG 37800 , ordinary least squares regression formulae were calculated using the shaft diameters at femoral 50\% and humeral distal $40 \%$ levels as the size proxy. The reference sample used in this analysis was 25 immature Macaca fuscata with individual body mass records ranging from 2.4 to $4.2 \mathrm{~kg}$, which essentially covers the estimated body mass of KNM-BG 37800 .

Skeletons of extant catarrhines were investigated at the National Museums of Kenya (Nairobi), Anthropological Institute and Museum (University of Zurich), Powell-Cotton Museum, Primate Research Institute (Kyoto University), and Japan Monkey Centre.

Since KNM-BG 37800 preserves a large part of the humerus and radius, the original lengths were estimated to obtain the brachial index. The humeral and radial lengths were measured following Schultz's (1930) definition: the humeral length is the greatest distance between the head of humerus and capitulum measured parallel to the longitudinal axis of the bone, and the radial length is the greatest distance between the radial head to the styloid process parallel to the longitudinal axis of the bone. In cases where the epiphyses of long bones are detached from the diaphysis (in comparative extant specimens), they were attached to the diaphysis with a small amount of clay when longitudinal length measurements were taken. For KNM-BG 37800, appropriate values for lost epiphyses were estimated from the comparative specimens of $P$. cynocephalus or $P$. heseloni. For the other measurements, definitions are noted in the text where relevant.

\section{Descriptions}

\section{Lumbar vertebra (KNM-BG 378000)}

The lumbar vertebra is crushed bilaterally by postmortem deformation (Figure 3). The cranial part of the body is skewed to the right and the caudal part to the left. The midventral part of the body is broken off. The transverse processes are broken from the base. The dorsal elements are relatively well preserved although deformed plastically. The prezygapophyses are eroded. The postzygapophysis is preserved on the left side. The spinous process survives from breakage although it is folded to the right by plastic deformation.

The transverse process arises from the widest part of the body, which is close to the centropedicular junction, in cranial view (Figure 3c, arrow). The pedicle is craniocaudally long and ca. $70 \%$ of the vertebral body height (measured on the left side). These features are common in adult $N$. kerioi as well as in Proconsul (Rose et al., 1996; Ishida et al., 2004; Nakatsukasa et al., 2007). The anapophyses are absent (Figure 3e), indicating this vertebra is not L1 since $N$. kerioi has anapophyses in at least one lumbar vertebra (Nakatsukasa et al., 2007).

The pedicle is completely fused with the body (Figure 3c). While this is common in non-hominoid catarrhines at the same dental developmental stage, it is unfused or incompletely fused (with an epiphyseal line) in living hominoids (Figure 4). There is no P. heseloni specimen in which the timing of pedicle-body fusion can be examined.

The base of the spinous process extends strongly caudally (Figure 3d), as is known for adult $N$. kerioi specimens (Nakatsukasa et al., 2007). The spinous process is low in dorsal projection but extends caudally (Figure $3 \mathrm{~b}$, e). The spinous process morphology clearly distinguishes $N$. kerioi from $P$. nyanzae and $P$. heseloni. In $P$. nyanzae, the lumbar spinous process projects much more dorsally (Ward, 1993). Although there is no $P$. heseloni specimen in which the whole lumbar spinous process is preserved, the spinous process base is more cranially restricted and projects dorsally (Figure $3 \mathrm{~h}$ ).

The vertebral body of the specimen is much smaller than that of the lumbar vertebrae (even L1) of the comparative $P$. cynocephalus infants. The cranial surface of the body is approximately $13 \mathrm{~mm}$ in transverse width and $6 \mathrm{~mm}$ in dorsoventral height. The dorsal length of the body is ca. $7 \mathrm{~mm}$. In the comparative $P$. cynocephalus infants, the average transverse width and dorsoventral height of the cranial surface at 


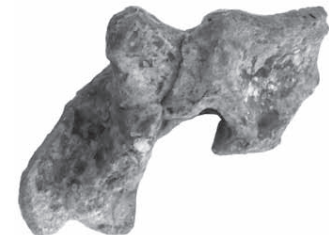

a

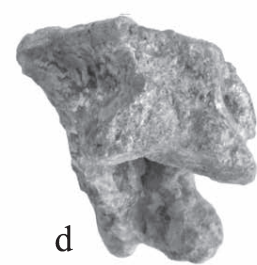

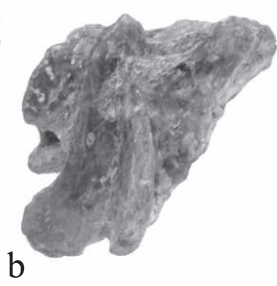

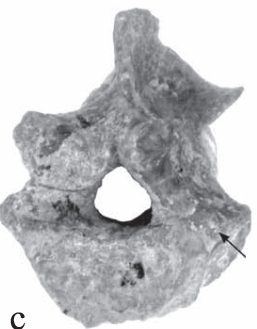

c

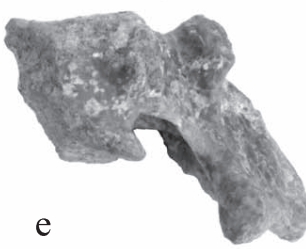

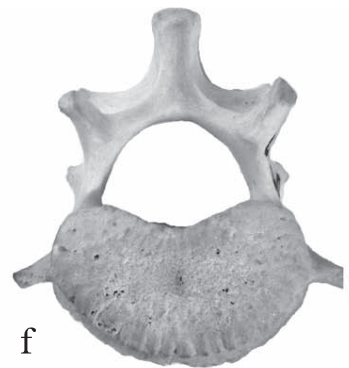

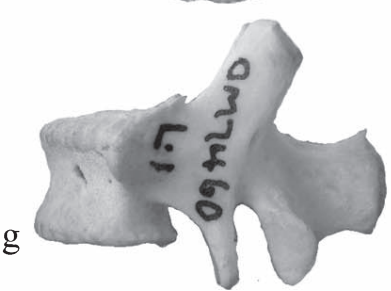

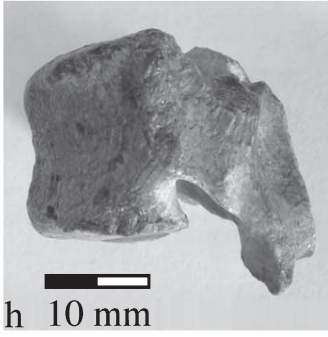

$10 \mathrm{~mm}$

Figure 3. N. kerioi lumbar vertebra KNM-BG 37800O: (a) right, (b) dorsal, (c) cranial, (d) ventral, (e) left view; infant Papio cynocephalus first lumbar vertebra KNM-OM 7460: (f) cranial, (g) left view; and juvenile P. heseloni lumbar vertebra KNM-RU 2036CY: (h) left view. Note caudally oriented spinous process, absence of the anapophysis, and smallness of the lumbar body in $N$. kerioi. In juvenile $P$. heseloni, the basal part of the broken spinous process projects dorsally. The arrow in (c) indicates the base of the transverse process.

Pan
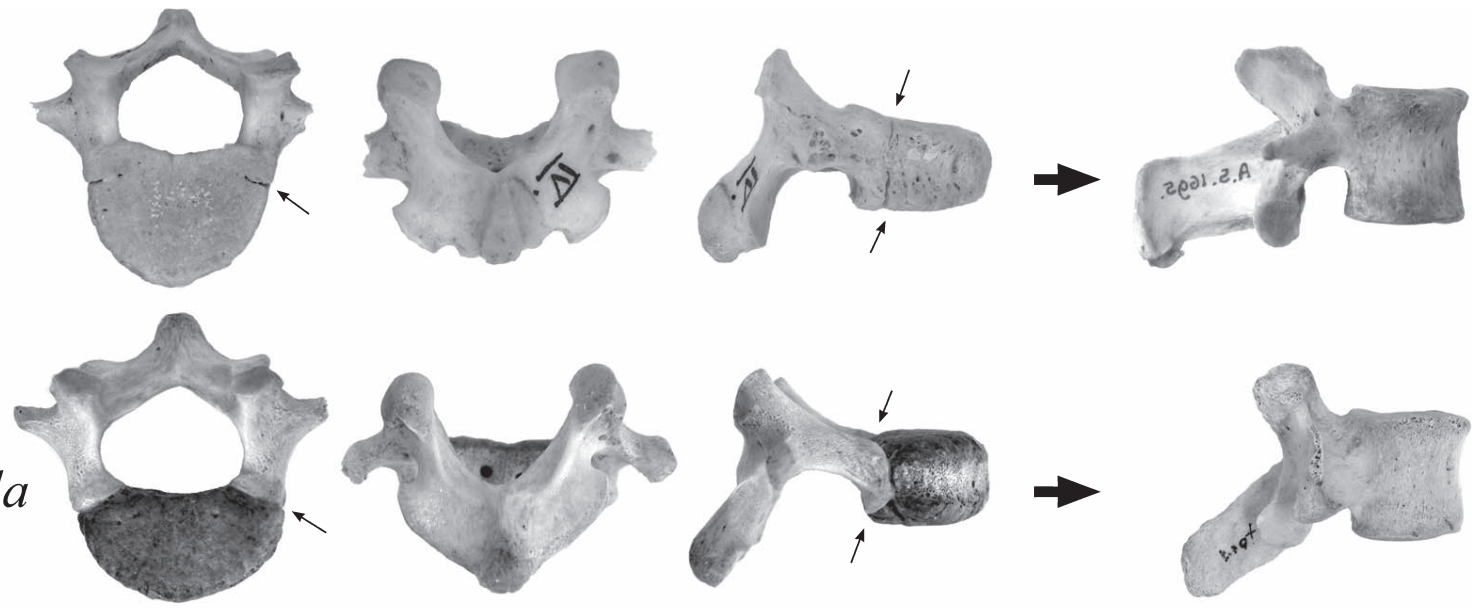

Gorilla
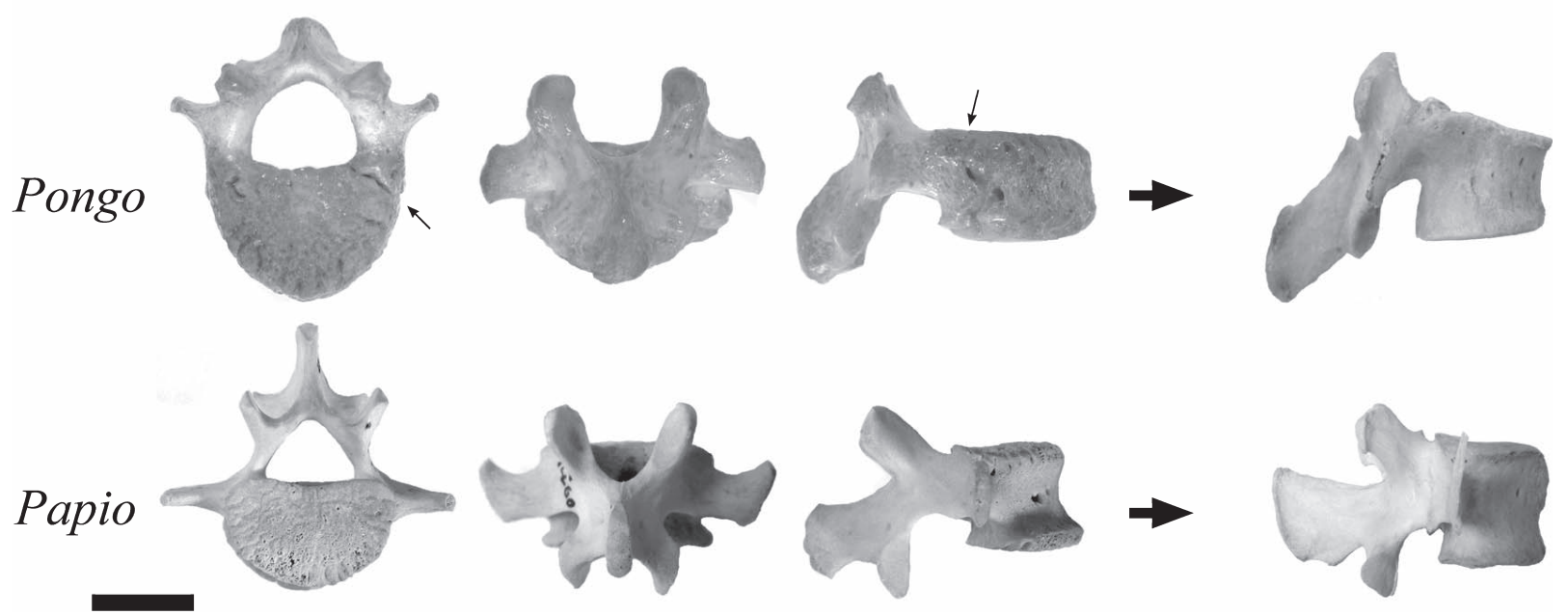

Figure 4. Mid-lumbar vertebrae of P. troglodytes, Gorilla gorilla, Pongo pygmaeus and P. cynocephalus (top to bottom). Left three columns, infant specimens which are similar to KNM-BG 38700 in dental stage (scale bar $=10 \mathrm{~mm}$ ). Far right column, adult specimens (not to scale). Small arrows indicate the epiphyseal line. Some specimens are shown in mirror image for comparative purpose. 
L1 are $16.1 \mathrm{~mm}$ (range: $14.5-17.2 \mathrm{~mm}$ ) and $7.8 \mathrm{~mm}$ (range: $7.0-8.6 \mathrm{~mm}$ ), respectively. While a straightforward comparison would be misleading since these measurements were taken from a severely deformed specimen, a significant size difference is readily recognized by visual inspection (Figure 3f, g). Compared to living catarrhines, adult $N$. keri$o i$ has small lumbar vertebral bodies relative to presumed body mass (Nakatsukasa, 2004; Nakatsukasa et al., 2007). KNM-BG 37800 shows that this feature is determined at an early stage of growth (for the body mass of KNM-BG 37800, see below). In a juvenile $P$. heseloni (KNM-RU 2036), a proportionally small lumbar vertebral body is also reported (Harrison and Sanders, 1999).

Irrespective of the small vertebral body, the dorsal elements of the lumbar vertebra are not particularly small (Figure 1e). For example, the post-zygaphophyseal articular surface is $5.0 \mathrm{~mm}$ in length and $3.7 \mathrm{~mm}$ in width (length $\times$ width $=18.5$ ). The average size of L1-L7 postzygapophysis [width $\times$ length $(\mathrm{mm})$ ] in the comparative infant baboons is 20.0, with an SD of $2.75(n=42)$. Large dorsal elements compared to the vertebral body are known in adult thoracic vertebrae of $N$. kerioi (Nakatsukasa et al., 2007).

\section{Scapula (KNM-BG 37800P)}

The left scapula is partially preserved (Figure 5). This specimen has been preliminarily described by Senut et al. (2004). For convenience, description is made referring to the human anatomical orientation, i.e. the glenoid faces laterally. This specimen preserves only the lateral part of the scap- ula, including the glenoid region and a proximal part of the scapular spine. The glenoid metaphysis has been narrowed by erosion (Figure 5a, gl). Cranial to the glenoid is the metaphysis of the coracoid process (Figure 5a, cor), which is intact. The cranial border is completely eroded. The axillary border is mostly eroded except for several millimeters adjacent to the glenoid metaphysis (Figure 5b).

The basal part of the scapular spine is intact. In cranial view, the spine deviates dorsally strongly (Figure $5 \mathrm{c}$ ). In dorsal view, the scapular spine diverges markedly from the cranial border of the scapula. This angle is somewhat emphasized by a fracture of the spine (Figure 5c, arrow). However, the notch at the spine base is very wide (Figure 5c, asterisk). This notch is wide in living apes, in association with a dorsally well-divergent scapular spine (Figure 6). The same was probably the case for $N$. kerioi. While a $P$. heseloni juvenile shows a relatively wide notch, it is less emphasized compared to the infant $N$. kerioi (Figure 6).

Senut et al. (2004) noted a large vertical distance between the axillary border and scapular spine base in adult $N$. kerioi and pointed out a similarity with some colobines and large cebids, as reported by Larson (1995) using comparative metrics in extant anthropoids. Because of the damage to the axillary border and erosion of the glenoid region, it is impossible to take the same measurements in the KNM-BG 37800P specimen. However, the basal pillar of the scapular spine arises from a high position alongside the glenoid metaphysis (Figure 5a, arrow). This pillar is located in a relatively low position in Papio and in a high position in Pan (Figure 5d, e), corresponding to the metric evaluations of Larson (1995).

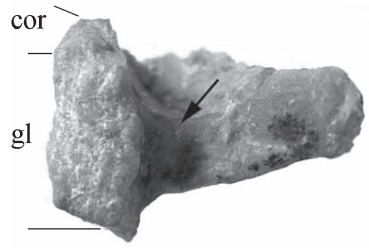

a

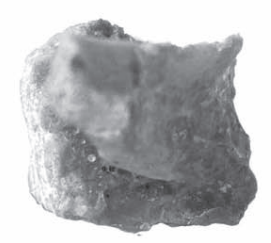

b

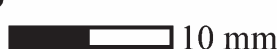

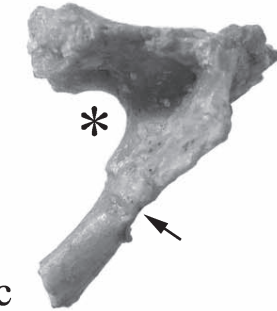

c

Figure 5. N. kerioi scapula KNM-BG 37800P: (a) lateral, (b) dorsal, (c) cranial view; scapulae of infant Papio cynocephalus KNM-OM 7460 (d); and Pan troglodytes KNM-OM 8439 (e) in lateral view. Note high position of the spine base (arrow in a) and wide notch at the spine base (asterisk in c) in N. kerioi. Papio (d) and Pan (e) specimens are not to scale.
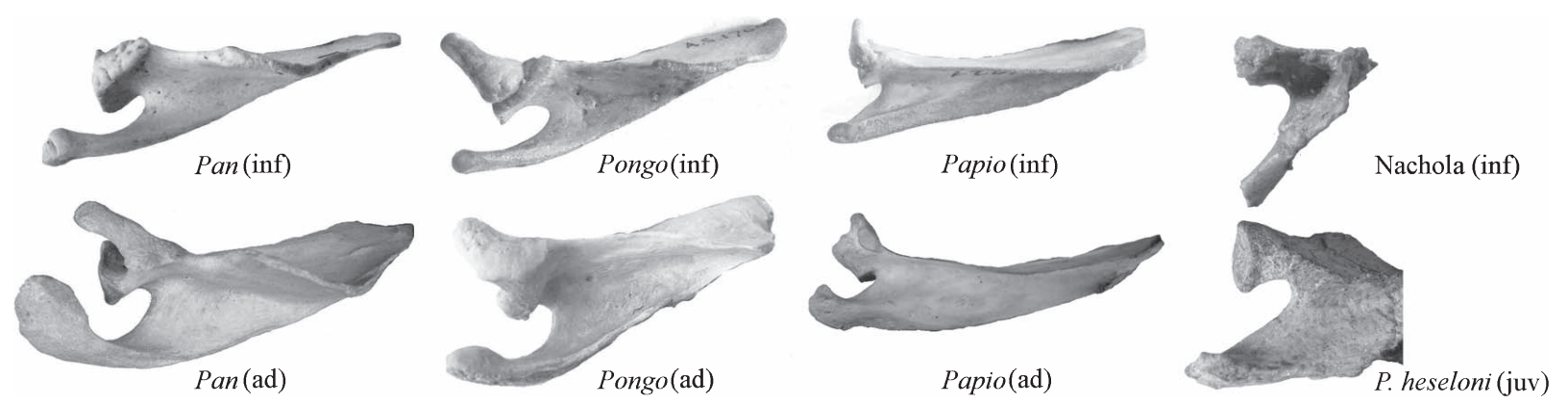

Figure 6. Scapula of some primates in cranial view to show morphological variation of the notch at the scapular spine base (not to scale). Abbreviations: inf, infant; jv, juvenile; ad, adult. The $P$. heseloni specimen (KNM-RU $2036 \mathrm{~A} / \mathrm{CH}$ ) is displayed in mirror image for comparison. 
Table 2. Measurements of the humerus, radius, and femur in infant fossil hominoids and P. cynocephalus (in mm)

\begin{tabular}{|c|c|c|c|c|c|c|c|}
\hline & \multirow[t]{2}{*}{ Length } & \multicolumn{2}{|c|}{ Humerus } & \multirow{2}{*}{$\begin{array}{l}\text { Radius } \\
\text { length }\end{array}$} & \multirow[t]{2}{*}{ Length } & \multicolumn{2}{|c|}{ Femur } \\
\hline & & $\begin{array}{l}\text { a-p diameter at } \\
\text { distal } 40 \%\end{array}$ & $\begin{array}{c}\text { m-l diameter at } \\
\text { distal } 40 \%\end{array}$ & & & $\begin{array}{l}\text { a-p diameter at } \\
\text { mid-length }\end{array}$ & $\begin{array}{l}\text { m-l diameter at } \\
\text { mid-length }\end{array}$ \\
\hline KNM-BG 37800 & $107^{\mathrm{a}}$ & 6.8 & 6.8 & $95^{\mathrm{a}}$ & $?$ & $6.9^{\mathrm{b}}$ & $8.1^{\mathrm{b}}$ \\
\hline KNM-KPS 4 & $134^{\mathrm{a}}$ & 7.0 & 7.2 & - & $131^{\mathrm{d}}$ & $(6.6)^{\mathrm{b}, \mathrm{c}}$ & $(9.0)^{\mathrm{b}, \mathrm{c}}$ \\
\hline $\begin{array}{l}\text { P. cynocephalus infant } \\
\text { Average and SD }(n=6)\end{array}$ & $104.2(5.71)$ & $7.2(0.52)$ & $6.9(0.47)$ & $107.8(3.60)$ & $124.8(4.79)$ & $7.3(0.32)$ & $7.3(0.33)$ \\
\hline
\end{tabular}

${ }^{a}$ Estimated value. The humeral length of KNM-KPS 4 was estimated by the same method as KNM-BG $37800 Q$ (see text). The length to the distal level of the deltopectoral crest is ca. $75 \mathrm{~mm}$ including the capitulum epiphysis.

$\mathrm{b}$ These measurements are taken at an approximate level.

${ }^{\mathrm{c}}$ Values in parenthesis may be subject to deformation.

${ }^{\mathrm{d}}$ The thickness of the distal epiphysis $(6 \mathrm{~mm}$ : the average in infants $P$. cynocephalus $)$ was added.

Thus, it is suggested that the scapular spine is set in a high position relative to the axillary border in the early developmental stage of $N$. kerioi. In juvenile $P$. heseloni (KNM-RU $2036 \mathrm{~A} / \mathrm{CH}$ ), a highly positioned pillar is observed (Senut et al., 2004).

\section{Humerus (KNM-BG 37800Q)}

The distal half of the left humerus is preserved (Figure 7, Table 2). It is $59 \mathrm{~mm}$ long proximodistally. The epiphyses of the capitulum, trochlea, and medial epicondyle are missing (Figure 7d). Although the shaft adjacent to the break is cracked, computerized tomography (CT) scans indicate the shaft is intact below this level (Figure 7, inset). On the anterior surface there is a sharp deltopectoral crest ca. $4 \mathrm{~mm}$ long running from the proximal break. A sharp deltopectoral crest is also present in juvenile $P$. heseloni (Napier and Davis, 1959). The deltopectoral crest disappears at the proximal $42-47 \%$ level (mean $=44 \%$ ) of humeral length in the comparative infant baboons. Similar values are obtained in juvenile samples of New World monkeys, Papio, and Cercopithecus $[42-44 \%$ of the species/generic average (Napier and Davis, 1959)]. Thus, to estimate the original length, we employed a value of $44 \%$ ( $56 \%$ of the total length from the distal end) for the distal level of the deltopectoral crest. Five millimeters were added to $59 \mathrm{~mm}$ in order to account for the missing capitulum epiphysis. This value was determined based on the humerus of KPS 4 and the P. cynocephalus infants. The original length is then estimated as $107 \mathrm{~mm}$. When this length is used, the anteroposterior and mediolateral diameters at the distal $40 \%$ level are both $6.8 \mathrm{~mm}$. The olecranon fossa is only partially preserved since the posterior cortex of the distal shaft is widely collapsed into the medullary cavity (Figure 7c). The olecranon fossa of the infant $N$. kerioi is shallow and the articular surface extends for only a short extent into the fossa (Figure 7c).

The coronoid fossa is deeper and more clearly defined than the radial fossa (Figure 8), which is a feature observed in adult $N$. kerioi (Ishida et al., 2004). In infant $P$. heseloni, the coronoid fossa is less distinctive compared to KNM-BG 37800 (Figure 8). The lateral epicondyle of $N$. kerioi projects far laterally and the distal shaft is weakly asymmetric (Figure 8). The metaphysis of the medial epicondyle faces moderately posteromedially (Figure $7 d$ ), which reflects the adult $N$. kerioi condition (Ishida et al., 2004). In contrast,

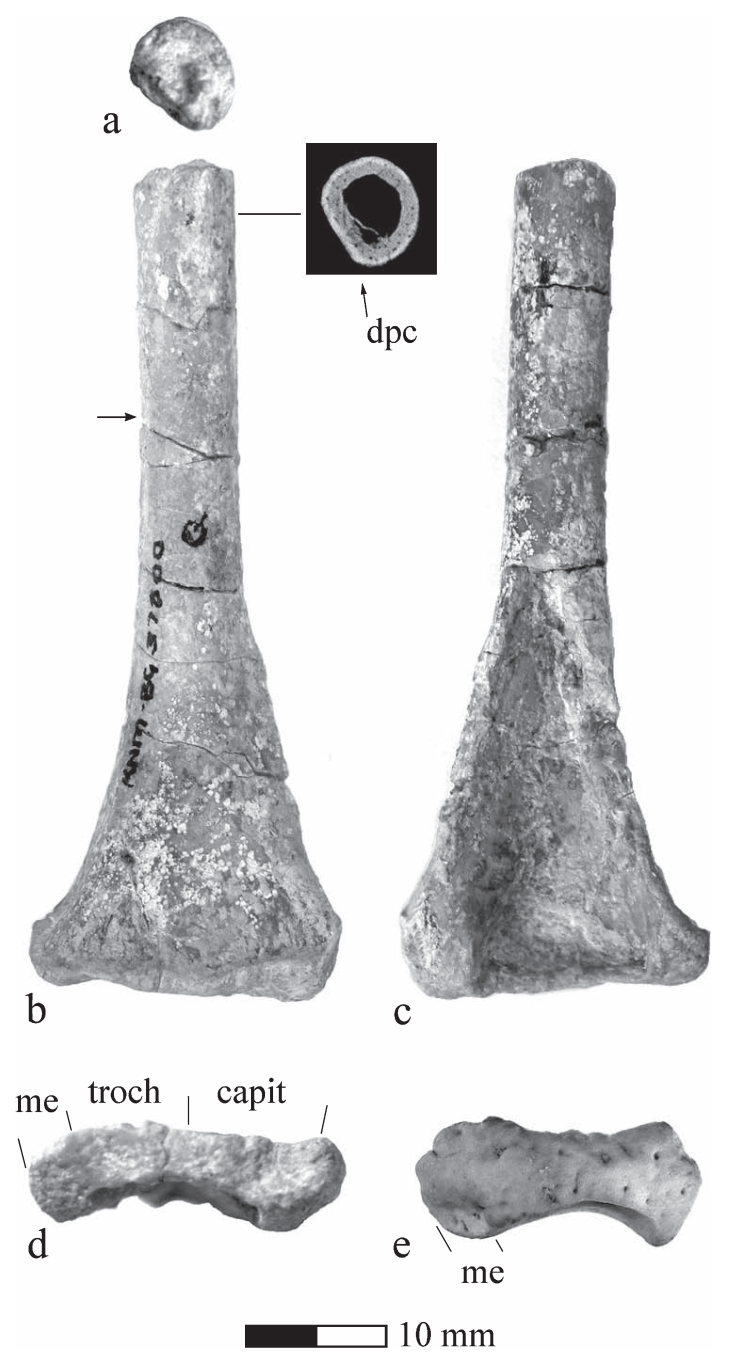

Figure 7. N. kerioi left humerus KNM-BG 37800Q: (a) proximal, (b) anterior, (c,) posterior, (d) distal views; inset, CT cross section near the break; and distal humeral epiphysis of an infant $P$. cynocephalus KNM-OM 7460: (e) distal view. Arrow indicates the presumed distal $40 \%$ level. Abbreviations: me, metaphysis for the medial condyle; troch, metaphysis for the trochlea; capit, metaphysis for the capitulum. 


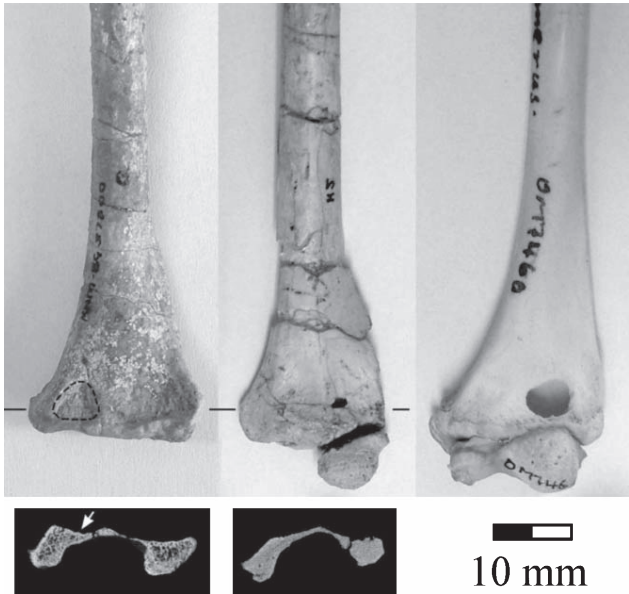

Figure 8. Distal humerus of infant N. kerioi (KNM-BG 37800Q), P. heseloni (KNM-KPS 4 H2), and P. cynocephalus (KNM-OM 7460) with CT cross-sectional images of the distal end (fossil specimens only: scan level is indicated by the thin line). For comparative purpose, the mirror image is shown for $P$. heseloni. Note a more pronounced coronoid fossa in $N$. kerioi (traced by broken line) than in P. heseloni. The coronoid fossa in $N$. kerioi is also indicated by an arrow in the CT image. No comparable depression is observed in P. heseloni.

infant baboons show a posteriorly facing metaphysis, reflecting a marked retroflexion of the medial condyle of the adults (Figure 7e).

\section{Ulna (KNM-BG 37800S)}

Only a short piece of the right proximal ulna is preserved (Figure 9a, b). It is $14.6 \mathrm{~mm}$ long proximodistally and broken below the radial notch. The epiphysis of the olecranon is detached. Although the posterior border of the olecranon metaphysis is obscure, the anterior part of the metaphysis, which faces proximally, is much larger than the posteroproximally facing posterior part (Figure 9b). In juvenile $P$. heseloni (KNM-RU 2036), the posterior part is larger than the anterior part. It is not clear if this difference corresponds to a difference in growth stage or to a species-specific difference since no adult specimen is available for $P$. heseloni. Adult $N$. kerioi ulnae exhibit a straight olecranon (Ishida et al., 2004). In baboon infants, the metaphysis faces mostly posteroproximally (Figure 9c), reflecting a retroflexed olecranon in adults.

Ossification of the articular surfaces is at an incipient stage. In adult $N$. kerioi, the articular surface at the trochlear notch is wide and is weakly convex mediolaterally and very extensive proximolaterally on the lateral side of the olecranon, and the coronoid process projects anteriorly and its superior surface is wide, moderately concave, and set horizontally (Ishida et al., 2004). None of these features is observed in the KNM-BG 37800S specimen. The olecranon beak is very short (Figure 9b). The coronoid process projects anterodistally rather than anteriorly, and is short and narrow. Its superior surface is convex mediolaterally rather than concave.

\section{Radius (KNM-BG 37800R)}

Much of the original length of the right radius is pre-

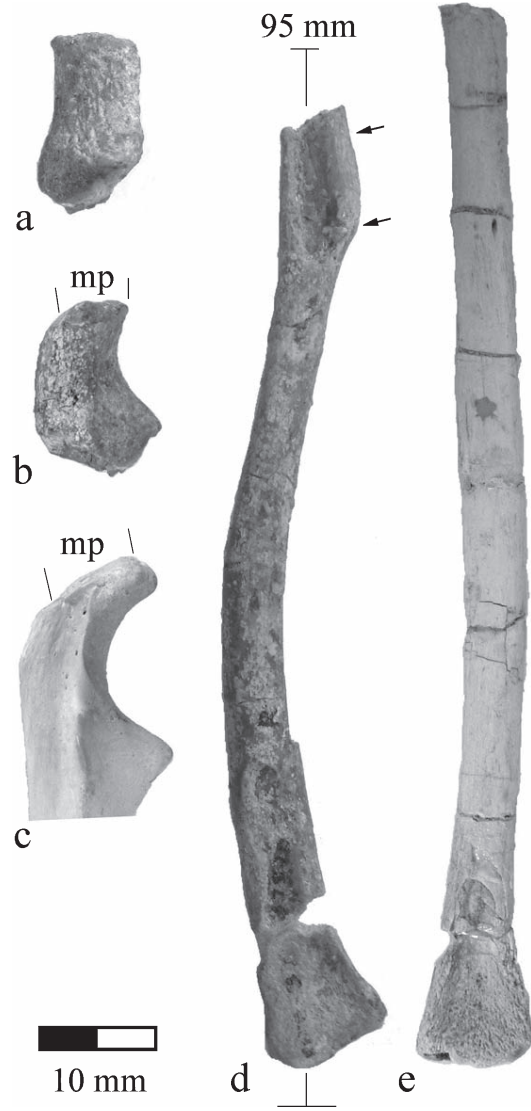

Figure 9. N. kerioi right ulna (KNM-BG 37800S) in anterior (a) and lateral (b) view, right ulna of an infant $P$. cynocephalus (KNM OM 7460 ) in lateral view (c), $N$. kerioi right radius KNM-BG 37800R in anterior view (d), and $P$. heseloni (KNM-KPS 4) left radius in anterior view (e). The olecranon metaphysis $(\mathrm{mp})$ is indicated in (b) and (c) Arrows in (e) indicate the proximal and distal border of the radial tuberosity. The original length of this radius is estimated as $95 \mathrm{~mm}$. Note that KNM-BG $37800 \mathrm{R}$ is considerably shorter than the radius of KNM-KPS 4, in which the shaft is broken distal to the radial tuberosity.

served, although few characteristic features are observable due to erosion and loss of the proximal and distal epiphyses. It is broken above the radial tuberosity (Figure 9d). The most proximal and distal parts are compressed anteroposteriorly by deformation. The length from the distal end to the break is $87 \mathrm{~mm}$. The length to the distal border of the radial tuberosity (Figure 9d, lower arrow) is $74 \mathrm{~mm}$. Although the shaft is markedly bowed laterally, this pronounced curvature is probably due to breakage around the mid-level. A partial radius (about distal half) of adult $N$. kerioi does not exhibit a sign of such a marked curvature (Ishida et al., 2004). The radial shaft of $P$. heseloni (KNM-KPS 4 R8) is much less curved compared to KNM-BG 37800R (Figure 9e). When measured along the curvature using a tape measure, the preserved length of KNM-BG $37800 \mathrm{R}$ is $89 \mathrm{~mm}$.

In the comparative infant baboons, the length from the distal epiphysis to the distal border of the radial tuberosity is ca. $85 \%$ of the bone length. If the same ratio is employed, the original length of the radius is calculated as $92 \mathrm{~mm}(4 \mathrm{~mm}$ were added to account for the distal epiphysis). If the strong 

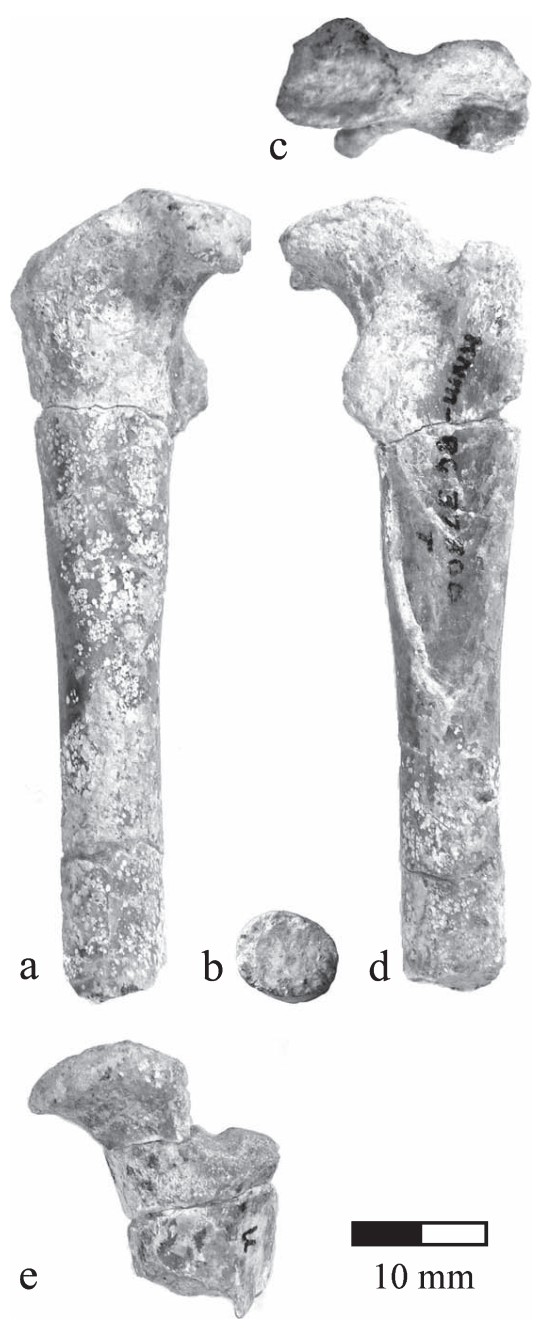

Figure 10. N. kerioi right femur (KNM-BG 37800T) in anterior (a), distal (b), proximal (c), posterior (d) views, and N. kerioi left femur (KNM-BG 37800U) in anterior view (e). curvature is actually a deformation, $95 \mathrm{~mm}$ would be a better estimate of the original length (Table 2).

\section{Femur (KNM-BG 37800T and U)}

Partial right and left femora are preserved. KNM-BG 37800 T is a proximal half of the right femur (Figure 10a-d). KNM-BG $37800 \mathrm{U}$ is a short piece of the left proximal femur, which is broken below the lesser trochanter (Figure 10e). Due to its better preservation, only the right femur is described.

KNM-BG $37800 \mathrm{~T}$ is $62.4 \mathrm{~mm}$ long from the top of the femoral head metaphysis to the distal break along the longitudinal shaft axis. Epiphyses of the head and the greater and lesser trochanters are detached. The neck is flattened anteroposteriorly due to postmortem compression. The posterior surface of the proximal shaft is widely collapsed.

The neck shaft angle is large $\left(138^{\circ}\right)$. In juvenile $P$. hesloni (KNM-RU 2036CL) this angle is somewhat smaller $\left(132^{\circ}\right)$. Although an adult $P$. hesloni specimen is not available, adult $P$. nyanzae also shows a relatively smaller value of around $130^{\circ}$ (MacLatchy et al., 2000).

It is impossible to estimate how much of the original length is preserved in KNM-BG 37800T, although visual inspection suggests that it probably represents $50-60 \%$. The femoral shaft in primates is usually narrowest at the mid- or slightly more distal level and expands distalwards. Shaft diameters change little along the distal most $1 \mathrm{~cm}$ of KNM-BG 37800T. At the distal break, the anterior-posterior (a-p) diameter of the shaft is $6.7 \mathrm{~mm}$ and the medial-lateral $(\mathrm{m}-\mathrm{l})$ diameter is $8.1 \mathrm{~mm}$. These measurements are considered to approximate those at the mid-length of the bone and were used to predict body mass (see below).

\section{Metapodial and phalanges}

One metapodial and seven phalangeal specimens were collected. Many are too fragmentary to be described and only relatively well-preserved specimens are presented here.

The metapodial specimen (KNM-BG $37800 \mathrm{~V}$ ) is a short proximal part (Figure 11a). Although surface erosion makes its assignment difficult, it is probably the left second or third

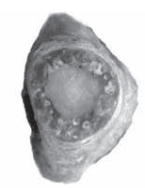

a

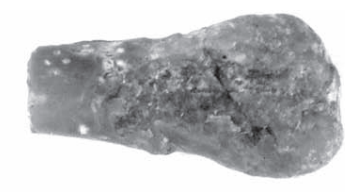

$\square \square$
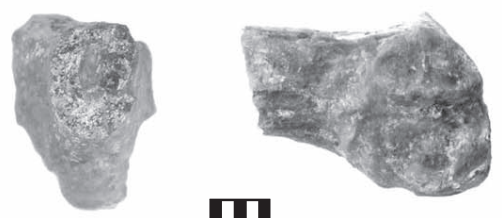
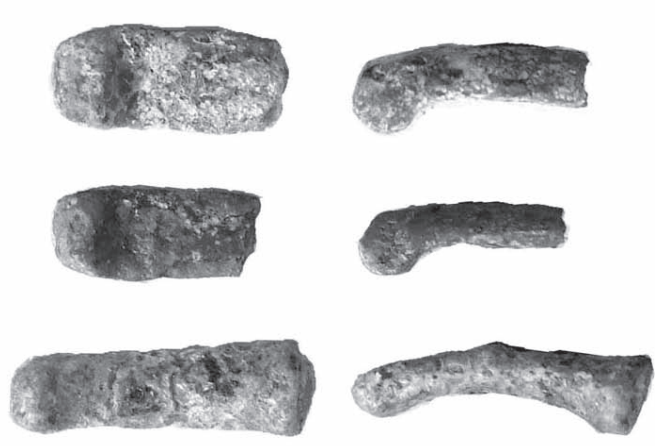

C

Figure 11. Metapodial and phalanges of N. kerioi: (a) metapodial fragment of an infant (KNM-BG 37800V) in distal and lateral views; (b) second metatarsal fragment of adult (KNM-BG 35250AK) in distal and lateral views; (c) phalanges associated with KNM-BG 37800 in ventral and lateral views, from top to bottom, KNM-BG 37800Y, Z and W. Scale bar $=5 \mathrm{~mm}$. 
metatarsal. At the break, the shaft is close to circular ( $3.1 \mathrm{~mm}$ mediolaterally and $3.3 \mathrm{~mm}$ dorsoventrally) and the cortical bone is evenly distributed. This condition differs from an adult second metatarsal specimen (KNM-BG $35250 \mathrm{AK})$ in which the shaft is thick dorsoplantarly (8.9 vs. $6.9 \mathrm{~mm}$ ) and the cortical bone is thicker plantarly (Figure 11b).

KNM-BG $37800 \mathrm{Y}$ and $\mathrm{Z}$ are the distal one-third or onefourth of the proximal phalanx (Figure 11c). KNM-BG $37800 \mathrm{Y}$ is somewhat larger than $\mathrm{Z}$ (Table 3 ) and exhibits a greater broadening of the distal shaft. This specimen is probably a manual phalanx. Compared to adult specimens, the trochlea is lower and secondary shaft features (Begun et al., 1994) are less developed. KNM-BG 37800W is a whole intermediate phalanx (Figure 11c). The proximal epiphysis is detached. It is $13.8 \mathrm{~mm}$ long. Compared to adult specimens, it is mediolaterally narrower (Table 3 ). The trochlea is relatively thick dorsoventrally compared to $P$. heseloni infants. This is also the case in adult comparisons (Nakatsukasa et al., 2003).

\section{Body mass}

The body mass of KNM-BG 37800 was estimated by prediction formulae based on 25 infant/juvenile Japanese macaque skeletons with known body mass. The a-p and $\mathrm{m}-1$ diameters of the shaft were measured at the mid-length of the femur and at the distal $40 \%$ of the humerus. The body mass was logarithmically scaled on the product of the a-p and $\mathrm{m}-\mathrm{l}$ diameters for each bone (Table 4).

Both regressions yield a predicted value of $3.0 \mathrm{~kg}[95 \%$ confidence intervals (CIs) were $2.7-3.4 \mathrm{~kg}$ in the femoral regression and $2.6-3.5 \mathrm{~kg}$ in the humeral regression]. Not surprisingly, this value roughly corresponds to that of the comparative $P$. cynocephalus individuals at a similar dental developmental stage. Using the same humeral regression, the body mass of KNM-KPS 4 is predicted as $3.2 \mathrm{~kg}(95 \%$ CI $2.7-3.8 \mathrm{~kg}$ ).

\section{Limb proportions}

Using the predicted humeral $(107 \mathrm{~mm})$ and radial (95 $\mathrm{mm}$ ) lengths, the brachial index was calculated as $89 \%$ for KNM-BG 37800. Napier and Davis (1959) estimated the brachial index of a juvenile $P$. heseloni (KNM-RU 2036) as $86 \%$. However, after additional limb bones belonging to this individual were discovered, Walker and Pickford (1983) recalculated the brachial index as $96.4 \%$. Compared to this value, the brachial index of KNM-BG 37800 is significantly lower. It is also very low compared with living catarrhines other than Gorilla and Homo (Table 5).

The brachial index may change through ontogeny. For example, the brachial index increases by $3.4 \%$ in P. troglodytes and $6.5 \%$ in $P$. cynocephalus from the infant to adult stages (Table 5). There is a significant difference between the means of infants and adults in each species $(p=0.0238$ in $P$. troglodytes and 0.001 in $P$. cynocephalus; two-tailed $t$-test). It seems possible that the low brachial index in KNM-BG 37800 would have increased through ontogeny. However, a drastic change would be required to cancel the difference from $P$. heseloni (Table 5).

\section{Discussion}

Gorilla and chimpanzee infants actively engage in independent locomotor behavior after 6 months of age, and species-specific locomotor characteristics start appearing by 2 years of age (Doran, 1992, 1997). The infant olive baboon (P. anubis) is close to infant $N$. kerioi in body mass, and exhibits a somewhat adult-like mode of performance of posi-

Table 3. Metric comparison of phalanges in N. kerioi and P. heseloni

\begin{tabular}{|c|c|c|c|c|c|}
\hline & Total length & Trochlea width & Trochlea height & $\begin{array}{l}\text { Trochlea width/total } \\
\text { length }(\%)\end{array}$ & $\begin{array}{c}\text { Trochlea height/ } \\
\text { width }(\%)\end{array}$ \\
\hline \multicolumn{6}{|l|}{ Proximal phalanx } \\
\hline $37800 \mathrm{Y}$ & - & 4.5 & 3.3 & - & 73.3 \\
\hline $37800 Z$ & - & 4.0 & 2.9 & - & 72.5 \\
\hline $\begin{array}{l}N \text {. kerioi adult hand and foot average } \\
\text { and SD }(n=4)\end{array}$ & - & $6.8(0.50)$ & $5.2(0.39)$ & - & $78.0(5.14)$ \\
\hline $\begin{array}{l}\text { KPS } 4 P \text {. heseloni hand and foot aver- } \\
\text { age and SD }(n=7)\end{array}$ & - & $4.2(0.39)$ & $2.9(0.20)$ & - & $70.4(2.88)$ \\
\hline \multicolumn{6}{|l|}{ Middle phalanx } \\
\hline $37800 \mathrm{~W}$ & 13.8 & 3.3 & 2.1 & 23.9 & 63.6 \\
\hline$N$. kerioi adult foot average $(n=2)$ & 24.6 & 6.9 & 4.4 & 27.9 & 64.2 \\
\hline $\begin{array}{l}\text { KPS } 4 P \text {. heseloni hand and foot aver- } \\
\text { age and SD }(n=4-6)\end{array}$ & $14.3(1.55)$ & $3.6(0.20)$ & $2.0(0.17)$ & $26.6(1.69)$ & $54.1(2.14)$ \\
\hline
\end{tabular}

Table 4. Body mass prediction $(\mathrm{kg})$

\begin{tabular}{|c|c|c|c|c|}
\hline Predictor (shaft dimension) & Ordinary least squares regression & $r^{2}$ & $\begin{array}{l}\text { Estimation for KNM- } \\
\text { BG } 37800\end{array}$ & $\begin{array}{l}\text { Estimation for KNM- } \\
\text { KPS } 4\end{array}$ \\
\hline $\begin{array}{l}\text { Femoral shaft a-p } \times \mathrm{m}-\mathrm{l} \text { at } 50 \% \\
\left(\mathrm{~mm}^{2}\right)\end{array}$ & $\ln (B M)=0.783 \times \ln ($ shaft dimension $)-2.058$ & 0.895 & $3.0(95 \%$ CI $2.7-3.4)$ & - \\
\hline $\begin{array}{l}\text { Humeral shaft a-p } \times \mathrm{m}-1 \text { at distal } \\
40 \%\left(\mathrm{~mm}^{2}\right)\end{array}$ & $\ln (B M)=0.768 \times \ln ($ shaft dimension $)-1.849$ & 0.819 & $3.0(95 \%$ CI $2.6-3.5)$ & $3.2(95 \%$ CI $2.7-3.8)$ \\
\hline
\end{tabular}


tional activities at 5-6 months of age (Rose, 1977). Therefore, it is reasonable to presume that KNM-BG 37800 , which is probably aged 6-15 months, was already engaged in active independent locomotion. In the present study, we observed that infant $P$. cynocephalus skeletons, at the equivalent dental growth stage to KNM-BG 37800, exhibited development of some terrestrially specialized postcranial features, e.g. dorsally oriented medial epicondyle metaphysis, posteroproximally facing olecranon metaphysis, and high brachial index (Jolly, 1967) (Table 5, Figure 7, Figure 9). Likewise, KNM-BG 37800 exhibits species-specific postcranial features that discriminate it clearly from the $P$. heseloni infant at a similar dental growth stage, presumably in association with active independent positional behavior. It is probable that positional behavioral differentiation between these fossil hominoids is initiated at a relatively early stage of postnatal growth.

There is no adult $N$. kerioi specimen in which the lumbar spinous process is preserved intact. Based on the caudally situated spinous process base and its similarity to that of Pongo and Gorilla, in a previous study we suggested that the spinous process in $N$. kerioi was probably caudally oriented (Nakatsukasa et al., 2007). The lumbar spinous process revealed by KNM-BG 37800 is distinctively low and caudally oriented, as in modern apes (Figure 3, Figure 4). In Pan, this morphology changes through ontogeny and the spinous process becomes craniocaudally wide and projects more dorsally (Figure 4). Therefore, straightforward reconstruction of the adult condition from the lumbar vertebra of KNM-BG 37800 would be misleading. However, it is important to note that the spinous process morphology of $N$. kerioi infant is distinct from that of cercopithecid (Papio) infants. The functional adaptation of dorsal extensors that act on the lumbar spinous process (e.g. multifidus) in infant $N$. kerioi was probably similar to that of infant extant apes, suggesting stability of the lumbar spine rather than enhanced extensionflexion for progression.

In $N$. kerioi, the pedicle is completely fused with the body

Table 5. Brachial index in catarrhines

\begin{tabular}{|c|c|c|}
\hline Taxon & Brachial index (SD or range) & Source \\
\hline N. kerioi (infant) & 88.8 & this study \\
\hline P. heseloni (juvenile) & 96.4 & Walker and Pickford (1983) \\
\hline P. troglodytes (infant, $n=8$ ) & $89.7(1.2)$ & this study \\
\hline P. troglodytes (adult, $n=10$ ) & $93.1(3.7)$ & this study \\
\hline P. paniscus (adult, $n=10$ ) & $91.6(1.2)$ & Jungers (1985) \\
\hline G. gorilla (infant, $n=1)$ & 84.0 & this study \\
\hline G. gorilla (adult, $n=21)$ & $80.4(2.4)$ & Jungers (1985) \\
\hline P. pygmaeus (juvenile, $n=10$ ) & $98.9(-)$ & Napier and Davis (1959) \\
\hline P. pygmaeus (adult, $n=66$ ) & $100.6(-)$ & Napier and Davis (1959) \\
\hline Hylobates (juvenile, $n=9$ ) & $105.9(-)$ & Napier and Davis (1959) \\
\hline Hylobates (adult, $n=39$ ) & $112.7(-)$ & Napier and Davis (1959) \\
\hline P. cynocephalus (infant, $n=6$ ) & $103.7(4.2)$ & this study \\
\hline P. cynocephalus (adult, $n=12$ ) & $110.2(2.7)$ & this study \\
\hline Macaca (adult, $n=53$ ) & $97(90-104)$ & Napier (1981) \\
\hline Cercocebus (adult, $n=24$ ) & $99(90-110)$ & Napier (1981) \\
\hline Cercopithecus (adult, $n=73$ ) & $95(87-102)$ & Napier (1981) \\
\hline Nasalis larvatus (adult, $n=6$ ) & $104.8(2.3)$ & Jungers (1985) \\
\hline
\end{tabular}

Table 6. Postcranial traits observed in KNM-BG 37800 and comparison with P. heseloni

\begin{tabular}{|c|c|}
\hline N. kerioi (infant) & P. heseloni (growth stage in parenthesis) \\
\hline \multicolumn{2}{|l|}{ Lumbar vertebra } \\
\hline early body-pedicle fusion (compared to living apes) & unknown; but probably same as $N$. kerioi \\
\hline [caudally projecting spinous process] & more dorsally projecting (juvenile) \\
\hline small vertebral body relative to general skeletal size & same as $N$. kerioi (juvenile) \\
\hline \multicolumn{2}{|l|}{ Scapula } \\
\hline [strong dorsal divergence of the scapular spine] & less pronounced (juvenile) \\
\hline high position of the scapular spine & same as $N$. kerioi (juvenile) \\
\hline \multicolumn{2}{|l|}{ Humerus } \\
\hline sharp deltopectoral crest & same as $N$. kerioi (infant/juvenile) \\
\hline [coronoid fossa more developed than the radial fossa] & coronoid fossa is weakly developed (infant/juvenile) \\
\hline \multicolumn{2}{|l|}{ Femur } \\
\hline [high neck shaft angle] & lower than in $N$. kerioi (juvenile) \\
\hline \multicolumn{2}{|l|}{ Intermediate phalanx } \\
\hline [trochlea relatively tall] & lower (infant) \\
\hline \multicolumn{2}{|l|}{ Brachial index } \\
\hline [low, $89 \%$ ] & moderate, $96 \%$ (juvenile) \\
\hline
\end{tabular}

Differentiated character state from $P$. heseloni is shown in brackets [ ]. 
at this dental age (Figure 3c). The pedicle-body fusion of the lumbar vertebra in living hominoids is delayed compared to non-hominoid catarrhines (this is unknown for gibbons due to a lack of observable specimens). This is in contrast to pedicles that are completely fused (disappearance of the epiphyseal line) with the lumbar vertebral body in non-hominoid catarrhines before all the deciduous molars are completely erupted, and the pedicles are unfused or incompletely fused in living hominoids (Figure 4). In this regard, N. kerioi resembles living non-hominoid catarrhines. This distinction coincides with the position of the transverse process origin [vertebral body vs. pedicle: but in N. kerioi the lumbar transverse process base is positioned on the pedicle caudally and it lies on the body cranially (Nakatsukasa et al., 2007)] and is probably related to different functional adaptations of the dorsal intrinsic lumbar musculature among catarrhines. In living apes, the intrinsic dorsal muscles are less developed (Ward et al., 1993).

Another important finding of this study is the strong dorsal divergence of the scapular spine. The notch at the base of the scapular spine is wide in living apes, and is associated with a dorsally divergent scapular spine (Figure 6), although this feature is not marked at the infant stage. In juvenile $P$. heseloni (KNM-RU 2036CH), the notch is narrower compared to infant $N$. kerioi, suggesting a spine that is dorsally less divergent in the adult form. Senut et al. (2004) suggested that a bulky supraspinatus muscle might account for the dorsal divergence of the scapular spine in $N$. kerioi. This muscle is active during the support phase of quadrupedal walking or when the arm is elevated against gravity (Larson and Stern, 1989, 1992). Given the lack of terrestrial specialization in the postcranium of $N$. kerioi (Ishida et al., 2004; Nakatsukasa, 2004), the latter situation (e.g. reaching or arm protraction in climbing) is probably responsible for the development of $\mathrm{m}$. supraspinatus.

Infant $N$. kerioi shows a deep coronoid fossa, whereas the radial fossa is only weakly developed. The development of the coronoid fossa (and weaker radial fossa development) is noted as a derived trait of the African Middle Miocene hominoids relative to the Early Miocene members (Ward et al., 1999). Functional explanation for this feature has not yet been given. Living hominoids show a complex of traits conforming to the stability of the humeroulnar, humeroradial, and proximal radioulnar joints throughout flexion-extension and supination-pronation if compared to living non-hominoid anthropoids (Jenkins, 1973; Sarmiento, 1985; Rose, 1988). Considering that the emphasized development of the coronoid fossa relative to the radial fossa is observed only in hominoids among living anthropoids, it is likely that this feature is linked to osteological change in relation to joint stabilizing function. Specialized elbow features in N. kerioi relative to Proconsul which relate to pronation-supination (Ishida et al., 2004) may support this possibility. However, if currently known hominoids from the Early and Middle Miocene of Africa other than Morotopithecus bishopi are outgroup members relative to the clade that includes M. bishopi and living hominoids (MacLatchy et al., 2000), the relative development of the coronoid fossa should be a convergent feature and not relevant to a closer phylogenetic relation between Middle Miocene hominoids (e.g. Kenyapithecus, $N$. kerioi) and living hominoids relative to Early Miocene members such as Proconsul. Currently, there is no consensus on which is true (see Harrison, 2002, 2005).

We previously noted that the femur of $N$. kerioi has a relatively high neck-shaft angle, although metric data were not shown due to deformation (Ishida et al., 2004). The present study supports this observation. The obtained value is higher than that of juvenile and adult Proconsul. Unfortunately, little is known of whether there is ontogenetic change of the femoral neck-shaft angle in non-human primates and no femoral specimen of infant Proconsul is available for comparison. Therefore, this value should be treated carefully.

Adult $N$. kerioi has proximal and intermediate phalanges whose trochlea is relatively tall compared to those in adult $P$. heseloni (Nakatsukasa et al., 2003). Similar differences were observed in comparisons of infants in this study (Table 3 ), although the difference was less marked in the case of proximal phalanges. The dorsoventral dimension of the trochlea theoretically affects the moment arm of the flexors and articular dimension in contact. However, the available specimens are too fragmentary to argue functional or behavioral implications.

This is the first study to describe the brachial index in $N$. kerioi. The estimated brachial index of KNM-BG 37800 is remarkably low compared to that of $P$. heseloni (Table 5). A low brachial index resulted from either a longer humerus, a shorter forearm, or both. To determine which is the case, a body mass of $3.0 \mathrm{~kg}$ is applied for regression analysis of limb bone length on body mass in anthropoid taxa [Table 4 of Jungers (1985)]. The cercopithecine formulae predict a humeral length of $108.9 \mathrm{~mm}(95 \%$ CI 78.1-151.7) and a radial length of $107.6 \mathrm{~mm}$ (95\% CI 66.3-174.5). The cebid (excluding Ateles) formulae predict a humeral length of $112.1 \mathrm{~mm}$ (95\% CI 77.9-161.1) $\mathrm{mm}$ and a radial length of $102.6 \mathrm{~mm}$ (95\% CI 72.8-144.6). These formulae are based on adult samples and thus should be applied to the immature individual with care. However, it is safe to conclude that the low brachial index resulted from a short radius (which was estimated in KNM-BG 37800 as 95 mm) rather than a long humerus (estimated as $107 \mathrm{~mm}$ ). Since the humeral length is estimated from a fragmentary specimen, its accuracy might be problematic. Thus, the estimated brachial index should be viewed carefully. However, the radial length is based on a rather complete specimen and an extreme underestimate seems unrealistic unless $N$. kerioi had a quite long radial neck and head. The shortness of the radius is confirmed by visual comparison with infant $P$. heseloni. Although KNMBG 37800 is only slightly lighter than KNM-KPS 4 in estimated body mass, the radius is appreciably shorter (Figure 9).

It seems unlikely that a relatively short radius is retained in the adult stage when considering the suite of postcranial adaptations of the forelimb-dominated arboreal behaviors in N. kerioi (Nakatsukasa, 2004; Nakatsukasa et al., 2003; Senut et al., 2004; Ishida et al., 2004). The radius in $N$. kerioi might have undergone prolonged or accelerated growth in later growth stages compared to $P$. heseloni. If this is the case, the ontogenetic trajectory of forelimb growth in $N$. kerioi would have been different from that of $P$. heseloni. However, the 'shortness' of the radius might be a 
product of body mass overestimation, wrong length reconstruction, or individual variation. Any conclusion must await the discovery of an adult $N$. kerioi specimen in which the radial length and brachial index can be examined.

Overall, the results of this study support the previously proposed reconstruction of $N$. keiroi positional adaptation. Functional studies of various anatomical traits have suggested a combination of arboreal positional modes that does not involve frequent suspension, but does include vertical climbing, orthograde clambering, transferring, or bridging as important locomotor modes when compared with Proconsul (Rose et al., 1996; Senut et al., 2004; Nakatsukasa, 2004; Nakatsukasa et al., 1998, 2004; Ishida et al., 2004). Functional indications given by the newly identified traits of the lumbar vertebra and the scapular spine correctly fit this positional reconstruction. Only the short radius relative to presumed body mass presents a contradictory indication to this interpretation. To solve this problem, it is necessary to confirm whether this feature actually existed in adult $N$. kerioi.

\section{Acknowledgments}

This article is dedicated to the late Ethekon Kichoto (1963-2006) of Nachola village, who has assisted our fieldwork in Nachola and Samburu Hills enormously since the early $1980 \mathrm{~s}$. He is also one of the discoverers of KNM-BG 37800. We thank the Office of President, Republic of Kenya for research permission, Idle Farah, Emma Mbua, and other staff at the National Museums of Kenya, and the JSPS Nairobi research station for their help to this study. We are grateful to Gen Suwa and anonymous reviewers for their thoughtful comments on the manuscript. This study was financially aided by Grant-in-Aid (\#16370104, \#19207019) and the 21 st Century COE program (A14) from the JSPS.

\section{References}

Begun D.R., Teaford M.F., and Walker A. (1994) Comparative and functional anatomy of Proconsul phalanges from the Kaswanga Primate Site, Rusinga Island, Kenya. Journal of Human Evolution, 26: 89-165.

Benyon A.D., Dean M.C., Leakey M.G., Reid D.J., and Walker A. (1998) Comparative dental development and microstructure of Proconsul teeth from Rusinga Island, Kenya. Journal of Human Evolution, 35: 163-209.

Doran D.M. (1992) The ontogeny of chimpanzee and pygmy chimpanzee locomotor behavior: a case study of paedomorphism and its behavioral correlates. Journal of Human Evolution, 23: 139-157.

Doran D.M. (1997) Ontogeny of locomotion in mountain gorillas and chimpanzees. Journal of Human Evolution, 32: 323-344.

Godfrey L.R., Petto A.J., and Sutherland M.R. (2002) Dental ontogeny and life-history strategies: The case of the giant extinct indrioids of Madagascar. In: Plavcan J.M., Kay R.F., van Schaik C.P., and Jungers W.L. (eds.), Reconstructing Behavior in the Primate Fossil Record. Kluwer, New York, pp. 113-157.

Godfrey L.R., Schwartz G.T., Samonds K.E., Jungers W.L., and Catlett K.K. (2006) The secrets of lemur teeth. Evolutionary Anthropology, 15: 142-154.

Harrison T. (2002) Late Oligocene to middle Miocene catarrhines from Afro-Arabia. In: Hartwig, W.C. (ed.), The Primate Fossil Record. Cambridge University Press, Cambridge, pp. 311338.
Harrison T. (2005) The zoogeographic and phylogenetic relationships of early catarrhine primates in Asia. Anthropological Science, 113: 43-51.

Harrison T. and Sanders W.J. (1999) Scaling of lumbar vertebrae in anthropoid primates: its implications for the positional behavior and phylogenetic affinities of Proconsul. American Journal of Physical Anthropology, Suppl. 28: 146.

Hurov J.R. (1991) Rethinking primate locomotion: what can we learn from development? Journal of Motor Behavior, 23: 211-218.

Ishida H., Kunimatsu Y., Takano T., Nakano Y., and Nakatsukasa M. (2004) Nacholapithecus skeleton from the Middle Miocene of Kenya. Journal of Human Evolution, 46: 67-101.

Jenkins F.A. (1973) The functional anatomy and evolution of the mammalian humero-ulnar articulation. American Journal of Anatomy, 137: 281-298.

Jolly C.J. (1967) The evolution of baboons. In: Vagtborg H. (ed.), The Baboon in Medical Research. University of Texas Press, Austin, pp. 23-50.

Jungers W.L. (1985) Body size and scaling of limb proportions in primates. In: Jungers W.L. (ed.), Size and Scaling in Primate Biology. Plenum Press, New York, pp. 345-381.

Kelley J. (1997) Paleobiological and phylogenetic significance of life history in Miocene hominoids. In: Begun D.R., Ward C.V., and Rose M.D. (eds.), Function, Phylogeny, and Fossils: Miocene Hominoid Evolution and Adaptations. Plenum Press, New York, pp. 173-208.

Kelley J. and Smith T.M. (2003) Age at first molar emergence in early Miocene Afropithecus turkanensis and life-history evolution in the Hominoidea. Journal of Human Evolution, 44: 307-329.

Kelley J., Dean M.C., and Reid D.J. (2001) Molar growth in the late Miocene hominoid, Dryopithecus laietanus. In: Brooks A. (ed.), Dental Morphology 2001. Sheffield Academic Press, Sheffield, pp. 123-134.

Larson S.G. (1995) New characters for functional interpretation of primate scapulae and proximal humeri. American Journal of Physical Anthropology, 98: 13-35.

Larson S.G. and Stern J.T. (1989) Role of supraspinatus in the quadrupedal locomotion of vervets (Cercopithecus aethiops): implication for interpretation of humeral morphology. American Journal of Physical Anthropology, 79: 369-377.

Larson S.G. and Stern J.T. (1992) Further evidence for the role of supraspinatus in quadrupedal monkeys. American Journal Physical Anthropology, 87: 359-363.

Lee P.C. and Foley R.A. (1993) Ecological energetics and extinction of giant gelada baboons. In: Jablonski N. G. (ed.), Theropithecus: The Rise and Fall of a Primate Genus. Cambridge University Press, Cambridge, pp. 487-498.

MacLatchy L., Gebo D., Kityo R., and Pilbeam D. (2000) Postcranial functional morphology of Morotopithecus bishopi, with implications for evolution of modern ape locomotion. Journal of Human Evolution, 39: 159-183.

Nakatsukasa M., Yamanaka A., Kunimatsu Y., Shimizu D., and Ishida H. (1998) A newly discovered Kenyapithecus skeleton and its implications for the evolution of positional behavior in Miocene East African hominoids. Journal of Human Evolution, 34: 657-664.

Nakatsukasa M., Kunimatsu Y., Nakano Y., Takano T., and Ishida H. (2003) Comparative and functional anatomy of phalanges in Nacholapithecus kerioi, a Middle Miocene hominoid from northern Kenya. Primates, 44: 371-412.

Nakatsukasa M. (2004) Acquisition of bipealism: the Miocene hominoid record and modern analogues for bipedal protohominids. Journal of Anatomy, 204: 384-402.

Nakatsukasa M., Kunimatsu Y., Nakano Y., Shimizu D., Tsujikawa H., and Ishida H. (2005) An infant skeleton of Nacholapithecus and ontogenetic development of postcranial features. American Journal of Physical Anthropology, Suppl. 40: 154155. 
Nakatsukasa M., Kunimatsu Y., Nakano Y., and Ishida H. (2007) Vertebral morphology of Nacholapithecus kerioi based on KNM-BG 35250. Journal of Human Evolution, 52: 357-369.

Napier J.R. and Davis P.R. (1959) The fore-limb skeleton and associated remains of Proconsul africanus. Fossil Mammals of Africa, 16: 1-69.

Napier P.H. (1981) Catalogue of Primates in the British Museum (Natural History) and Elsewhere in the British Isles. Part II. British Museum (Natural History), London.

Ravosa M.J. and Vinyard C.J. (2002) On the interface between ontogeny and function. In: Plavcan J.M., Kay R.F., van Schaik C.P., and Jungers W.L. (eds.), Reconstructing Behavior in the Primate Fossil Record. Kluwer, New York, pp. 73111.

Rose M.D. (1977) Positional behavior of Olive baboons (Papio anubis) and its relationship to maintenance and social activities. Primates, 18: 59-116.

Rose M.D. (1988) Another look at the anthropoid elbow. Journal of Human Evolution, 17: 193-224.

Rose M.D., Nakano Y., and Ishida H. (1996) Kenyapithecus postcranial specimens from Nachola, Kenya. African Study Monographs, Suppl. 24: 3-56.

Sarmiento E.E. (1985) Functional differences in the skeleton of wild and captive orang-utans and their adaptive significance. Ph.D. Thesis, New York University.

Schultz A.H. (1930) The skeleton of the trunk and limbs of the higher primates. Human Biology, 2: 303-408.

Schwartz G.T., Samonds K.E., Godfrey L.R., and Jungers W.L. (2002) Dental microstructure and life history in subfossil Malagasy lemurs. Proceedings of National Academy of Sci- ences of the United States of America, 99: 6124-6129.

Senut B., Nakatsukasa M., Kunimatsu Y., Nakano Y., Takano T., Tsujikawa H., Shimizu D., Kagaya M., and Ishida H. (2004) Preliminary analysis of Nacholapithecus scapula and clavicle from Nachola, Kenya. Primates, 45: 97-104.

Smith B.H., Crummett T.K., and Brandt K.L. (1994) Ages of eruption of primate teeth: a compendium for aging individuals and comparing life histories. Yearbook of Physical Anthropology, 37: $177-231$.

Walker A.C. and Pickford M. (1983) New postcranial fossils of Proconsul africanus and Proconsul nyanzae. In: Ciochon R.L. and Corruccini R.S. (eds.), New Interpretations of Ape and Human Ancestry. Plenum Press, New York and London, pp. 325-351.

Walker A. and Teaford M. (1988) The Kaswanga Primate Site: an Early Miocene hominoid site on Rusinga Island, Kenya. Journal of Human Evolution, 17: 539-544.

Ward C.V. (1991) Functional anatomy of the lower back and pelvis of the Miocene hominoid Proconsul nyanzae from Mfwangano Island, Kenya. Ph. D. Thesis, The Johns Hopkins University.

Ward C.V. (1993) Torso morphology and locomotion in Proconsul nyanzae. American Journal of Physical Anthropology, 92: 291-328.

Ward C.V., Walker A., Teaford M.F., and Odhiambo I. (1993) Partial skeleton of Proconsul nyanzae from Mfangano Island. American Journal of Physical Anthropology, 90: 77-111.

Ward S., Brown B., Hill A., Kelley J., and Downs W. (1999) Equatorius: a new hominoid genus from the middle Miocene of Kenya. Science, 285: 1382-1386. 